\title{
Underweight BMI Values and their Influence on Prosthetic Breast Reconstruction 30-Day Outcomes
}

Jon $\mathbf{P}$ Ver Halen $\mathbf{M D}^{1^{*}}$, Lauren M Mioton BS $^{2}$ and John YS Kim MD ${ }^{3}$

${ }^{1}$ Division of Plastic and Reconstructive Surgery, Baptist Cancer Center, Vanderbilt-Ingram Cancer Center, St. Jude Children's Research Hospital, Memphis, TN, USA

${ }^{2}$ Vanderbilt School of Medicine, Nashville, TN, USA

${ }^{3}$ Division of Plastic and Reconstructive Surgery, Northwestern University, Feinberg School of Medicine, Chicago, Illinois, USA

\begin{abstract}
Background: Risk factors for breast reconstruction have been widely studied. However, the impact of underweight BMI values on outcomes has not yet been examined.

Methods: The American College of Surgeons National Surgical Quality Improvement Program (ACS-NSQIP) database was retrospectively reviewed for all patients who underwent prosthetic breast reconstruction between 2006 and 2011. Underweight (BMI<18.5) and normal weight (reference, BMI 18.5-24.99) patients were included in the final analysis. Multivariate logistic regression models were used to determine independent predictors of complications.

Results: The underweight and normal weight patient cohorts were well-matched. When compared to the normal weight population, underweight patients displayed decreased rates of total complications, surgical complications, and reoperation. On multivariate analysis, patients with a BMI in the underweight category trended toward lower risk for total and surgical complications. The sum of total relative value units (RVUs) was a significant risk factor for total complications (OR 1.014, $\mathrm{p}=0.047$ ).

Conclusion: Through this analysis of over 1,600 patients, we reveal that underweight patients $(B M \mid<18.5)$ receiving prosthetic breast reconstruction did not have any significant differences in adverse events than their normal weight counterparts. As more patients are collected in NSQIP, it will be possible to delineate between those with underweight due to lean body mass versus chronic diseases, allowing more granular analysis of the relationship between underweight
\end{abstract} status and outcomes after breast reconstruction.

Keywords: Prosthetic breast reconstruction; Underweight; Complications

\section{Introduction}

Obesity and elevated body mass index (BMI) have been a focus of contemporary medical research, largely due to their contributions to adverse medical outcomes [1]. Conversely, low BMI has recently been described as a risk factor for medical and surgical adverse events (AE) [2-4]. Several recent studies on critically and chronically ill patients suggest that underweight patients have an increased risk for death and catastrophic complications [5-11]. However, low BMI may be a result of physical fitness, as opposed to chronic illness. Recent literature has detailed an association between obesity and poor surgical outcomes in the breast reconstruction population [12-19]. In contrast, very little has been written about the risk of underweight patients undergoing breast reconstruction surgery. Studies attempting to do so have been compromised by small sample sizes, single-institutional bias and inconsistent definitions of underweight [20-22].

In an effort to better understand the influence of underweight BMI on outcomes following breast reconstruction, we examined the National Surgical Quality Improvement Program (NSQIP) datasets. We aimed to define and benchmark the risks and outcomes following prosthetic breast reconstruction - the most popular reconstruction method globally - utilizing a detailed analysis of underweight patients.

\section{Methods}

\section{Data source}

The information incorporated into the NSQIP database is extracted from patient medical records, physician office records, and telephone interviews by trained surgical clinical nurse reviewers (SCNRs). Intensive training sessions for the nurse reviewers have helped ensure the reliability of the data, as studies have revealed a low rate $(1.96 \%)$ of inter-observer disagreement across variables [23]. All information is subsequently de-identified and is made freely available to all institutional members who comply with the NSQIP Data Use Agreement.

\section{Patient population}

All patients with 'Plastics' recorded as their primary surgical team was isolated from the 2006-2011 NSQIP databases. Prosthetic breast reconstruction patients were subsequently identified by standardized procedural description codes - a variable tracked in the database (i.e., CPT code 19357). Those who underwent multiple types of breast reconstruction were excluded. Patients with an underweight BMI, defined as $\mathrm{BMI}<18.5$, or a normal range BMI (18.5-24.99) were included in the final analysis.

\section{Outcomes}

Our primary outcomes of interest were: 30-day surgical

*Corresponding author: Jon $\mathrm{P}$ Ver Halen, MD FACS, Division of Plastic, Reconstructive, and Hand SurgeryBaptist Cancer Center/Vanderbilt Ingram Cancer Center/ St. Jude Children's Research Hospital, 3268 Duke CircleGermantown, TN, USA 38139, Tel: (206) 963-8714; Fax: (901) 227-9825;E-mail: jpverhalen@gmail. com

Received August 08, 2014; Accepted October 28, 2014; Published November 04, 2014

Citation: Ver Halen JPMD, Mioton LMDS, Kim JYSMD, Zezi AU, Maikai VA (2015) Underweight BMI Values and their Influence on Prosthetic Breast Reconstruction 30-Day Outcomes. Biol Med (Aligarh) 7: 215. doi: 10.4172/0974-8369.1000215

Copyright: () 2015 Ver Halen JPMD, et al. This is an open-access article distributed under the terms of the Creative Commons Attribution License, which permits unrestricted use, distribution, and reproduction in any medium, provided the original author and source are credited. 
Citation: Ver Halen JPMD, Mioton LMDS, Kim JYSMD, Zezi AU, Maikai VA (2015) Underweight BMI Values and their Influence on Prosthetic Breast Reconstruction 30-Day Outcomes. Biol Med (Aligarh) 7: 215. doi: 10.4172/0974-8369.1000215

complications, medical complications, reoperation, and mortality. Surgical complications were defined as having $\geq 1$ of the following ACS-NSQIP post-operative adverse events: superficial surgical site infection (SSI), deep SSI, organ/space SSI, wound disruption/ dehiscence, or graft/prosthesis failure. Medical complications included: pneumonia, unplanned intubation, pulmonary embolism, failure to wean from ventilator, renal insufficiency, progressive renal failure, urinary tract infection, stroke, coma, peripheral neurologic deficiency, cardiac arrest, myocardial infarction, bleeding requiring a transfusion, deep venous thrombosis (DVT), and sepsis/septic shock. Reoperation was defined as any unplanned return to the operating room for surgical intervention within 30 days. Mortality was defined as death within 30 days of the index procedure.

\section{Statistical Analysis}

Prosthetic reconstruction patients were stratified into underweight and normal weight (reference) BMI categories. Patient demographics and clinical characteristics - including diabetes, hypertension, chemotherapy within 30 days, radiation within 90 days, and chronic steroid or immunosuppression use - were tracked as potential confounders. Alcohol use and smoking were also tracked as behavioral risk factors. Albumin levels were only rarely available, and therefore were not included for analysis. Chi-square analysis was used to compare categorical variables and independent $\mathrm{T}$-tests were used to analyze continuous variables. Multivariable logistic regression analysis was utilized to investigate the impact of low BMI values on outcomes. Pre-operative variables with $\geq 10$ occurrences and $\mathrm{P} \leq .20$ on bivariate screening were included in the analysis. All analyses were conducted using SPSS version 21 (Chicago, IL).

\section{Results}

After review of the 25,346 plastic surgery patients extracted from the NSQIP database, we found 3,513 patients who received prosthetic reconstruction. Of these, 1,652 were included for analysis based on BMI criteria. Seventy-seven of included patients were underweight (i.e., $\mathrm{BMI}<18.5$ ), and the remaining 1,575 were normal weight (BMI 18.5-24.99). The average age of underweight patients undergoing prosthetic breast reconstruction was 51.1 years, compared to 50.0 years in the reference cohort $(p=0.431$, Table 1$)$. Hypertension was the most common comorbidity in tracked patients, and smoking was the most common high-risk characteristic. Following stratification of the population into BMI categories, we observed that rates of chronic obstructive pulmonary disease (COPD), dyspnea, active smoking, and alcohol use were all elevated in the underweight cohort, but none of these factors reached significance $(p>0.05)$. In addition, underweight patients had slightly higher relative value unit (RVU) totals and operative times $(p>0.05)$.

Total complications, surgical complications, and reoperation rates were all higher in the reference group compared to the underweight population-but these differences were not statistically significant (all $p>0.05$, Table 2). Specifically, total complications rose from $1.30 \%$ in underweight patients to $2.79 \%$ in normal weight patients $(p=0.720)$. Similarly, surgical complications rose from $1.30 \%$ to $1.78 \%(p=1.00)$ and reoperation rates increased from $0 \%$ to $3.05 \%(p=0.167)$. Only medical complications $(1.30 \%$ vs $0.51 \%, p=0.350)$ and organ/ space SSI rates $(1.30 \%$ vs $0.38 \%, p=0.284)$ were increased in the underweight population.

Multivariate regression analysis examined low BMI as a predictor of outcomes (Table 3). Our results showed that underweight status was not a risk factor for total complications, or surgical complications ( $p=0.440$ and 0.536 , respectively). The total RVU value - often used as a proxy for surgical complexity - carried a significant increased risk for total complications (OR 1.01 per additional RVU, 95\% CI $1.00-1.03$, $p=0.047$ ).

\section{Discussion}

This study defines and benchmarks the 30-day risks and outcomes after prosthetic breast reconstruction in underweight patients. By drawing data from a large, prospective cohort identified within the 2006-2011 NSQIP datasets, we endeavored to examine the impact of underweight BMI on prosthetic breast reconstruction outcomes in a manner representative of the national population. While surgical outcomes have been well documented in obese patients, this work represents the first population-based assessment of the impact of underweight BMI values $(\mathrm{BMI}<18.5)$ on 30 -day outcomes following prosthetic breast reconstruction [15-17].

We found a total of 3,513 patients who underwent prosthetic

\begin{tabular}{|c|c|c|c|c|c|}
\hline & \multicolumn{2}{|c|}{ Underweight } & \multicolumn{2}{|c|}{ Normal Weight } & $p$-values \\
\hline & \multicolumn{2}{|c|}{$<18.5$} & \multicolumn{2}{|c|}{ 18.5-24.99 } & \\
\hline & \multicolumn{2}{|c|}{$\mathrm{n}=77$} & \multicolumn{2}{|c|}{$\mathrm{n}=1575$} & \\
\hline & $\mathrm{n}$ & $\%$ & $\mathrm{n}$ & $\%$ & \\
\hline Age & \multicolumn{2}{|c|}{$51.08 \pm 11.99$} & \multicolumn{2}{|c|}{$50.04 \pm 11.26$} & 0.431 \\
\hline Hypertension & 6 & $7.79 \%$ & 204 & $12.95 \%$ & 0.184 \\
\hline Diabetes & 1 & $1.30 \%$ & 26 & $1.65 \%$ & 1.000 \\
\hline COPD & 1 & $1.30 \%$ & 11 & $0.70 \%$ & 0.437 \\
\hline Dyspnea & 2 & $2.60 \%$ & 27 & $1.71 \%$ & 0.395 \\
\hline History of TIA or CVA & 0 & $0.00 \%$ & 7 & $0.44 \%$ & 1.000 \\
\hline Prior $\mathrm{PCl}$ or $\mathrm{PCS}$ & 0 & $0.00 \%$ & 16 & $1.02 \%$ & 1.000 \\
\hline Active Smoking & 13 & $16.88 \%$ & 219 & $13.90 \%$ & 0.371 \\
\hline Alcohol Use & 2 & $2.60 \%$ & 15 & $0.95 \%$ & 0.186 \\
\hline Chronic Steroid Use & 0 & $0.00 \%$ & 15 & $0.95 \%$ & 1.000 \\
\hline Wound Infection within 30 days & 1 & $1.30 \%$ & 30 & $1.90 \%$ & 1.000 \\
\hline Outpatient cases & 54 & $70.13 \%$ & 1174 & $74.54 \%$ & 0.387 \\
\hline Sum of Relative Value Units & \multicolumn{2}{|c|}{$34.30 \pm 17.90$} & \multicolumn{2}{|c|}{$33.54 \pm 19.33$} & 0.735 \\
\hline Operative time (hours) & \multicolumn{2}{|c|}{$2.27 \pm 2.18$} & \multicolumn{2}{|c|}{$2.10 \pm 1.27$} & 0.272 \\
\hline * denotes significant value, $p<.05$ & & & & & \\
\hline
\end{tabular}

Table 1: Prosthetic breast reconstruction patient clinical characteristics, stratified by BMI. (Independent T-test used for univariate statistical evaluation; significance set at $p<0.05$

\begin{tabular}{|l|c|c|c|}
\hline & Underweight & Normal Weight & \\
\hline & $<18.5$ & $18.5-24.99$ & \\
\hline & $\mathrm{n}=77$ & $\mathrm{n}=1575$ & \\
\hline Total Complications & $1.30 \%$ & $2.79 \%$ & 0.720 \\
\hline Surgical Complications & $1.30 \%$ & $1.78 \%$ & 1.000 \\
\hline Wound Infection & $1.30 \%$ & $1.90 \%$ & 1.000 \\
\hline Superficial SSI & $0.00 \%$ & $0.89 \%$ & 1.000 \\
\hline Deep SSI & $0.00 \%$ & $0.63 \%$ & 1.000 \\
\hline Organ/Space SSI & $1.30 \%$ & $0.38 \%$ & 0.284 \\
\hline Dehiscence & $0.00 \%$ & $0.57 \%$ & 1.000 \\
\hline Prosthesis Failure & $0.00 \%$ & $0.13 \%$ & 1.000 \\
\hline Medical Complications & $1.30 \%$ & $0.51 \%$ & 0.350 \\
\hline Reoperation & $0.00 \%$ & $3.05 \%$ & 0.167 \\
\hline Death & $0.00 \%$ & $0.00 \%$ & - \\
\hline
\end{tabular}

Table 2: Post-operative complications following prosthetic breast reconstruction, stratified by BMI. (Independent T-test used for univariate statistical evaluation; significance set at $p<0.05$. 
Citation: Ver Halen JPMD, Mioton LMDS, Kim JYSMD, Zezi AU, Maikai VA (2015) Underweight BMI Values and their Influence on Prosthetic Breast Reconstruction 30-Day Outcomes. Biol Med (Aligarh) 7: 215. doi: 10.4172/0974-8369.1000215

Page 3 of 5

\begin{tabular}{|c|c|c|c|c|c|c|c|c|}
\hline \multirow{2}{*}{ Variable } & \multicolumn{4}{|c|}{ Total Complications } & \multicolumn{4}{|c|}{ Surgical Complications } \\
\hline & OR & $95 \%$ & $\mathrm{Cl}$ & p-value & OR & $95 \%$ & $\mathrm{Cl}$ & $p$-value \\
\hline BMI category & \multirow{2}{*}{0.456} & \multirow{2}{*}{0.062} & \multirow{2}{*}{3.356} & \multirow{2}{*}{0.440} & \multirow{2}{*}{0.532} & \multirow{2}{*}{0.072} & \multirow{2}{*}{3.928} & \multirow{2}{*}{0.536} \\
\hline Underweight (BMI <18.5) & & & & & & & & \\
\hline Normal weight (BMI 18.5-24.99) & \multicolumn{3}{|c|}{ reference } & & \multicolumn{4}{|c|}{ reference } \\
\hline Sum of Relative Value Units (RVU) & 1.014 & 1.000 & 1.028 & $0.047^{*}$ & - & - & - & - \\
\hline
\end{tabular}

* Denotes significant value, $p<0.05$

Table 3: Multivariate Regression Analysis.

breast reconstruction during the study period. BMI stratification of this population revealed that $2.2 \%$ were underweight $(\mathrm{BMI}<18.5)$ and $44.8 \%$ were normal weight (BMI 18.5-24.99). Underweight patients were nearly the same age as the normal weight (reference) population and also displayed a lower incidence of preoperative comorbidities, with the exception of COPD, dyspnea, active smoking, and alcohol use. There was also a slight decrease in the number of outpatient cases and a slight increase in RVUs and operative time in the underweight cohort, although these differences were not significant [24-28].

While considerable attention has been focused on high BMI and breast reconstruction - with obese patients displaying increased rates of total complications - outcomes in underweight patients have been infrequently studied [20-22,29-31]. Our study suggests that patients with underweight BMI values do not have different rates of complications after implant-based breast reconstruction, compared to their normal-weight counterparts. We revealed that underweight patients displayed lower (but non-significant) rates of adverse events except for organ/space SSI and medical complications - when compared to normal weight patients. This finding is in contrast with many recent studies in other surgical fields, which found a paradoxical relationship between BMI and postoperative mortality - with underweight patients displaying higher mortality rates than obese individuals after both cardiac and non-cardiac surgery [3,4,32-40]. Multivariate logistic regression further showed that an underweight BMI was not an independent predictor of total or surgical complications. Our only finding of significance was between increased RVU totals and total complications. This is not surprising as RVU values are often representative of greater surgical complexity, and technically difficult procedures may have an inherently higher risk for complications. Of note, the underweight cohort displayed a greater sum of RVUs, on average, compared to the normal weight population. This may reflect an increased degree of surgical complexity in these patients, including the need for ADM utilization, serratus muscle flap coverage, and other procedures to obtain total implant coverage. A smaller proportion of outpatient cases and greater average operative times in the underweight population substantiate this explanation.

There are a number of factors confounding an investigation into low BMI and outcomes [30]. Certain findings suggest that the association between a low BMI and increased mortality is in part an artifact of preexisting disease. First, the association between underweight BMI and increased mortality has been found in previous studies to be substantially weaker after 15 years of follow-up (hazard ratio, 1.21) than after 5 years of follow- up (hazard ratio, 1.73) [30]. This finding is thought to correlate with greater confounding by other prevalent diseases that were either undiagnosed or not accounted for in the early years of follow-up. Specifically, chronic conditions that cause weight loss - namely cancer and respiratory and cardiac diseases - may remain unnoticed for months or even years; all of which could impact outcomes. It is also difficult for a large database to differentiate between persons with low BMI values who are physically active (i.e., those who were lean and fit) and persons with low BMI values who are inactive (i.e., those with illness-induced wasting). In our cohort, albumin levels were too infrequently collected to be statistically evaluated. While our study is the largest such evaluation of underweight breast reconstruction patients, it is still too small to subdivide the cohort into patients who were underweight secondary to physical fitness versus chronic disease. As the dataset continues to collect patients, it may be ultimately possible to delineate these populations. It has been observed elsewhere that low BMI may reflect an aging population, with an increased incidence of low muscle mass and increased rates of comorbid disease [41]. However, in our database, underweight patients were not significantly older, and had fewer comorbid diseases than normal weight patients. In fact, the infrequent presence of comorbid disease in this population may have contributed to the lower morbidity rates in the cohort.

One important difference between our underweight cohort and the reference population was the incidence of active smoking ( $16.9 \%$ vs $13.9 \%, p=0.371)$. Active smoking is another potential confounding factor as it is associated with a decreased weight, and is also a well-established risk factor for surgical complications [30,31,42]. Interestingly smoking was not determined to be a potential risk factor for total or surgical complications on bivariate screening. Ultimately underweight patients - even with a higher percentage of active smokers - had lower (but non-significant) rates of surgical complications (OR $0.53, p=0.54$ ).

Although the ACS-NSQIP provides a useful database to conduct large observational studies, it has several limitations. First, the nature of the database limits the specific risk factors that can be evaluated to those that have been reported. For example, surgical details are underreported. Specifically, the database lacks information regarding mastectomy techniques (skin-sparing versus nipple-areola sparing) and fat transfer use. While timing of the procedure (i.e., immediate versus delayed) is known, we could not adequately investigate the impact of breast reconstruction timing due to limited patient population size. Patient factors that could impact outcomes, but are not reported in the database, include previous surgical procedures, degree of mammary ptosis, and breast size. Additionally, the duration of postoperative drains has been shown to be a significant risk factor for SSI in breast surgeries, but it is a variable that is not collected by the NSQIP database [43]. Several other common procedure-specific complications including hematoma, seroma, and fat necrosis are not captured in the datasets. Furthermore, the database does not include information on previous breast conservation therapy failure, disease stage, tumor burden, or postoperative radiation therapy - all of which may play a role in the development of complications. Finally, the database is limited to 30 -day outcomes, thereby reducing our ability to evaluate longer term outcomes, including long-term aesthetic results. Underweight patients could have a greater number of long term complications from thinner skin coverage over implants - including capsular contracture, the need for reoperation, and even reconstructive failure, which would not be captured in a 30-day postoperative window. We acknowledge that additional breast reconstruction procedures may 
Citation: Ver Halen JPMD, Mioton LMDS, Kim JYSMD, Zezi AU, Maikai VA (2015) Underweight BMI Values and their Influence on Prosthetic Breast Reconstruction 30-Day Outcomes. Biol Med (Aligarh) 7: 215. doi: 10.4172/0974-8369.1000215

Page 4 of 5

have been coded under other surgical specialties; our decision to isolate cases performed only by 'Plastics' as the primary service likely limited our patient sample size. However, we chose this method to provide data unadulterated by additional surgical specialties, as any findings would then be directly attributed to board-certified plastic surgeons. Even with these fastidious patient selection criteria, the robust, multiinstitutional nature of the NSQIP database offers a unique platform to conduct large scale analyses. Specifically, we were able to isolate over 1,600 patients undergoing prosthetic breast reconstruction to examine the heretofore undefined relationship between underweight status and postoperative outcomes.

Regardless of these limitations, our study has numerous implications for research, medical practice, and society. Patients, surgeons, and insurance payers must be aware that underweight status alone does not appear to confer an increased risk for adverse events after prosthetic breast reconstruction. It does confer a slightly increased use of surgical services and hospital length of stay, although these differences are not significant. Future research should be spent refining the NSQIP database to discern between patients who are underweight secondary to physical fitness, versus chronic disease, and in explaining the above-mentioned differences in resource utilization in the underweight population.

\section{Conclusion}

This study represents the only review to date of post-mastectomy prosthetic breast reconstruction in underweight patients. We reveal that, compared to normal weight patients, underweight patients undergoing prosthetic breast reconstruction have equivalent 30-day adverse events profiles. These data provide important information to patients, surgeons, and insurance payers for informed consent and risk stratification. As the NSQIP database evolves, it will possibly allow further delineation of underweight patients into lean/fit patients versus those suffering from chronic diseases.

\section{Financial Support}

This research received no specific grant from any funding agency in the public, private, or not for-profit sectors. Lauren M. Mioton is funded on a research scholarship through Vanderbilt University School of Medicine by NIH CTSA Grant UL1RR024975.

\section{Conflict of Interest Statement}

The authors have no financial disclosures relevant to this paper.

\section{Ethical Approval}

This study did not undergo Institutional Review Board approval as it is a retrospective review of data that was de-identified prior to distribution to participating institutions. De-identified patient information is freely available to all institutional members who comply with the ACS-NSQIP Data Use Agreement. The Data Use Agreement implements the protections afforded by the Health Insurance Portability and Accountability Act of 1996 and the ACS-NSQIP Hospital Participation Agreement.

\section{Disclaimer}

The American College of Surgeons National Surgical Quality Improvement Program and the hospitals participating in the ACS NSQIP are the source of the data used herein; they have not verified and are not responsible for the statistical validity of the data analysis or the conclusions derived by the authors.

\section{References}

1. Ogden CL, Carroll MD, Kit BK, Flegal KM (2012) Prevalence of obesity in the United States, 2009-2010. NCHS Data Brief : 1-8.

2. Abedi NN, Davenport DL, Xenos E, Sorial E, Minion DJ, et al. (2009) Gender and 30-day outcome in patients undergoing endovascular aneurysm repair (EVAR): an analysis using the ACS NSQIP dataset. J Vasc Surg 50: 486-491, 491

3. Mullen JT, Davenport DL, Hutter MM, Hosokawa PW, Henderson WG, et al. (2008) Impact of body mass index on perioperative outcomes in patients undergoing major intra-abdominal cancer surgery. Ann Surg Oncol 15: 2164 2172

4. Mullen JT, Moorman DW, Davenport DL (2009) The obesity paradox: body mass index and outcomes in patients undergoing nonbariatric general surgery. Ann Surg 250: 166-172.

5. Tremblay A, Bandi V (2003) Impact of body mass index on outcomes following critical care. Chest 123: 1202-1207.

6. O'Brien JM Jr, Phillips GS, Ali NA, Lucarelli M, Marsh CB, et al. (2006) Body mass index is independently associated with hospital mortality in mechanically ventilated adults with acute lung injury. Crit Care Med 34: 738-744.

7. Curtis JP, Selter JG, Wang Y, Rathore SS, Jovin IS, et al. (2005) The obesity paradox: body mass index and outcomes in patients with heart failure. Arch Intern Med 165: 55-61.

8. Fonarow GC, Srikanthan P, Costanzo MR, Cintron GB, Lopatin M; ADHERE Scientific Advisory Committee and Investigators (2007) An obesity paradox in acute heart failure: analysis of body mass index and inhospital mortality for 108,927 patients in the Acute Decompensated Heart Failure National Registry. Am Heart J 153: 74-81.

9. Gruberg L, Weissman NJ, Waksman R, Fuchs S, Deible R, et al. (2002) The impact of obesity on the short-term and long-term outcomes after percutaneous coronary intervention: the obesity paradox? J Am Coll Cardiol 39: 578-584.

10. Gurm HS, Brennan DM, Booth J, Tcheng JE, Lincoff AM, et al. (2002) Impact of body mass index on outcome after percutaneous coronary intervention (the obesity paradox). Am J Cardiol 90: 42-45

11. Obesity and Overweight (2012) World Health Organization Fact sheet No 311 USA.

12. Christian CK, Niland J, Edge SB, Ottesen RA, Hughes ME, et al. (2006) A multi-institutional analysis of the socioeconomic determinants of breast reconstruction: a study of the National Comprehensive Cancer Network. Ann Surg 243:241-249.

13. Alderman AK, Wilkins EG, Kim HM, Lowery JC (2002) Complications in postmastectomy breast reconstruction: two-year results of the Michigan Breast Reconstruction Outcome Study. Plast Reconstr Surg 109: 2265-2274.

14. Atisha DM, Alderman AK, Kuhn LE, Wilkins EG (2008) The impact of obesity on patient satisfaction with breast reconstruction. Plast Reconstr Surg 121 1893-1899.

15. Nguyen KT, Hanwright PJ, Smetona JT, Hirsch EM, Seth AK, et al. (2014) Body mass index as a continuous predictor of outcomes after expander-implant breast reconstruction. Ann Plast Surg 73: 19-24.

16. Wink JD, Fischer JP, Nelson JA, Serletti JM, Wu LC (2014) Direct-to-implant breast reconstruction: An analysis of 1612 cases from the ACS-NSQIP surgical outcomes database. J Plast Surg Hand Surg.

17. Fischer JP, Cleveland EC, Nelson JA, Kovach SJ, Serletti JM, et al.(2013) Breast reconstruction in the morbidly obese patient: assessment of 30-day complications using the 2005 to 2010 National Surgical Quality Improvement Program data sets. Plast Reconstr Surg 132:750-61.

18. Klasen J, Junger A, Hartmann B, Jost A, Benson M, et al. (2004) Increased body mass index and peri-operative risk in patients undergoing non-cardiac surgery. Obes Surg 14: 275-281.

19. Dindo D, Muller MK, Weber M, Clavien PA (2003) Obesity in general elective surgery. Lancet 361: 2032-2035.

20. Kim EK, Eom JS, Hwang $\mathrm{CH}$, Ahn SH, Son BH, et al. (2014) Immediate transverse rectus abdominis musculocutaneous (TRAM) flap breast reconstruction in underweight Asian patients. Breast Cancer 21: 693-697.

21. Wang HY, Ali RS, Chen SC, Chao TC, Cheng MH (2008) One-stage immediate breast reconstruction with implant following skin-sparing mastectomy in Asian patients. Ann Plast Surg 60: 362-366. 
Citation: Ver Halen JPMD, Mioton LMDS, Kim JYSMD, Zezi AU, Maikai VA (2015) Underweight BMI Values and their Influence on Prosthetic Breast Reconstruction 30-Day Outcomes. Biol Med (Aligarh) 7: 215. doi: 10.4172/0974-8369.1000215

Page 5 of 5

22. Albornoz CR, Cordeiro PG, Farias-Eisner G, Mehrara BJ, Pusic AL, et al. (2014) Diminishing relative contraindications for immediate breast reconstruction. Plast Reconstr Surg 134: 363e-369e.

23. Shiloach M, Frencher SK Jr, Steeger JE, Rowell KS, Bartzokis K, et al. (2010). Toward robust information: data quality and inter-rater reliability in the American College of Surgeons National Surgical Quality Improvement Program. J Am Coll Surg 210:6-16.

24. Meigs JB (2002) Epidemiology of the metabolic syndrome, 2002. Am J Manag Care 8: S283-292.

25. Cemal Y, Albornoz CR, Disa JJ, McCarthy CM, Mehrara BJ, et al. (2013) A paradigm shift in U.S. breast reconstruction: Part 2. The influence of changing mastectomy patterns on reconstructive rate and method. Plast Reconstr Surg 131: $320 \mathrm{e}-6 \mathrm{e}$.

26. Barnett K, Mercer SW, Norbury M, Watt G, Wyke S, et al. (2012) Epidemiology of multimorbidity and implications for health care, research, and medical education: a cross-sectional study. Lancet 380: 37-43.

27. Quesenberry CP Jr, Caan B, Jacobson A (1998) Obesity, health services use, and health care costs among members of a health maintenance organization. Arch Intern Med 158: 466-472.

28. Liu JH, Etzioni DA, O'Connell JB, Maggard MA, Ko CY (2004) The increasing workload of general surgery. Arch Surg 139: 423-428.

29. Khavanin N, Lovecchio FC, Hanwright PJ, Brill E, Milad M, et al. (2013) The influence of BMI on perioperative morbidity following abdominal hysterectomy. Am J Obstet Gynecol 208: 449.

30. Berrington de Gonzalez A, Hartge P, Cerhan JR, Flint AJ, Hannan L, et al. (2010) Body-mass index and mortality among 1.46 million white adults. N Engl J Med 363: 2211-2219.

31. Whitlock G, Lewington S, Sherliker P, Clarke R, et al. (2009) Body-mass index and cause-specific mortality in 900000 adults: collaborative analyses of 57 prospective studies. Prospective Studies Collaboration, Lancet 373: 1083-1096.

32. Giles KA, Hamdan AD, Pomposelli FB, Wyers MC, Siracuse JJ, et al. (2010) Body mass index: surgical site infections and mortality after lower extremity bypass from the National Surgical Quality Improvement Program 2005-2007. Ann Vasc Surg 24: 48-56.
33. Giles KA, Wyers MC, Pomposelli FB, Hamdan AD, Ching YA et al. (2010) The impact of body mass index on perioperative outcomes of open and endovascular abdominal aortic aneurysm repair from the National Surgical Quality Improvement Program, 2005-2007. J Vasc Surg 52: 1471-1477.

34. Morgan MA, Lewis WG, Hopper AN, Escofet X, Harvard TJ, et al. (2007) Prognostic significance of body mass indices for patients undergoing esophagectomy for cancer. Dis Esophagus 20: 29-35.

35. Reeves BC, Ascione R, Chamberlain MH, Angelini GD (2003) Effect of body mass index on early outcomes in patients undergoing coronary artery bypass surgery. J Am Coll Cardiol 42: 668-676

36. Shirzad M, Karimi A, Armadi SH, Marzban M, Abbasi K, et al. (2009) Effects of body mass index on early outcome of coronary artery bypass surgery. Minerva Chir 64: 17-23.

37. Habib RH, Zacharias A, Schwann TA, Riordan CJ, Durham SJ, et al. (2005) Effects of obesity and small body size on operative and long-term outcomes of coronary artery bypass surgery: a propensity-matched analysis. Ann Thorac Surg 79: 1976-1986.

38. Prabhakar G, Haan CK, Peterson ED, Coombs LP, Cruzzavala JL, et al. (2002) The risks of moderate and extreme obesity for coronary artery bypass grafting outcomes: a study from the Society of Thoracic Surgeons' database. Ann Thorac Surg 74: 1125-1130.

39. Engel AM, McDonough S, Smith JM (2009) Does an obese body mass index affect hospital outcomes after coronary artery bypass graft surgery? Ann Thorac Surg 88: 1793-1800.

40. Valentijn TM, Galal W, Tjeertes EK, Hoeks SE, Verhagen HJ, et al. (2013) The obesity paradox in the surgical population. Surgeon 11: 169-176.

41. Ward SA, Parikh S, Workman B (2011) Health perspectives: international epidemiology of ageing. Best Pract Res Clin Anaesthesiol 25: 305-317.

42. Khullar D, Maa J (2012) The impact of smoking on surgical outcomes. J Am Coll Surg 215: 418-426.

43. Clayton JL, Bazakas A, Lee CN, Lee CN, Hultman CS, Halvorson EG (2012) Once is not enough: withholding postoperative prophylactic antibiotics in prosthetic breast reconstruction is associated with an increased risk of infection Plast Reconstr Surg 130:495-502. 